syndrome present with a variety of 'neurotic' symptoms. The patients also offer 'loss of semen' as the explanation for these disabling symptoms. Such patients are diagnosed as having dhat syndrome if the physician is aware of the label and the explanation, and if he or she focuses on the content. These patients could also receive a label of anxiety, depression or somatisation if the physician emphasises the form of the presentation. The patient perspective of 'loss of semen' as the cause of the symptoms would then be perceived as the patient's explanatory model of his illness.

It has long been recognised that contemporary themes are often incorporated into psychopathology. The culture in south Asia tends to highlight sexual causes for a variety of neurotic phenomena. These explanations generate more acceptance and understanding for the patient than anxiety, depression or somatic symptoms would. Such beliefs are reinforced by traditional Indian systems of medicine which subscribe to these concepts and whose physicians and healers are often the first contact in the pathway to care. Thus, such beliefs are reinforced and perpetuated.

Sexual misconceptions related to dhat are also observed among patients with schizophrenia, substance dependence, bipolar disorders, delusional disorders and major depression.

The focus on form allows psychiatrists to differentiate the different syndromes (Sims, 1988). International classifications have emphasised form over content as a response to the various treatment modal ities, based on the recognition and treatment of the clinical syndrome. This does not imply reduced importance being placed on the person's culture and beliefs. It would mandate the management of the patient's explanatory model. This is also true for other culture-bound syndromes such as koro.

Clinicians focusing on content make such presentations appear exotic. Physicians emphasising form are able to recognise behavioural syndromes across cultures. The management of patients with such presentations is the same, irrespective of the diagnostic labels employed.

Sims, A. (1988) Symptoms in the Mind: An Introduction to Descriptive Psychopathology, p. 12. London: Baillière Tindall.

Sumathipala, A., Siribaddana, S. H. \& Bhugra, D. (2004) Culture-bound syndromes: the story of dhat syndrome. British Journal of Psychiatry, 184, 200-209.

G. Rajesh, K. S. Jacob Department of Psychiatry, Christian Medical College, Vellore 632002, India
Author's reply: Drs Rajesh and Jacob's suggestion of a dichotomy between form and content is an interesting one. We acknowledge that some patients' explanations for their distress may be linked to their perception of semen loss or dhat. Drs Rajesh and Jacob highlight that contemporary themes are incorporated into psychopathology, and we agree. However, it is interesting to note that patients with dhat appear to latch on to a more traditional explanation. The 'disappearance' of similar complaints in the West may be related to changes in socio-economic conditions. The distinction between form and content of a number of psychopathological symptoms is well worth studying and ripe for further research. We think the suggestion that management is the same, irrespective of the diagnostic labels is simplistic - the cultural explanations of distress and their understanding is paramount in delivering services that will be acceptable and in providing treatments that will be adhered to by patients.

D. Bhugra Section of Cultural Psychiatry, PO25, Institute of Psychiatry, London SE5 8AF, UK

\title{
One hundred years ago
}

\section{The problem of the feeble-minded}

DR. TREDGOLD's paper read at the Guildhall Conference on the Feeble-minded has now been printed, and will be found to contain a very succinct discussion of the sociological bearings of the efforts now being widely made to improve the condition of the mentally defective class. He points out "that with the exigencies of civilized life, the demands upon the intellectual faculties of the individual become daily more exacting", and consequently that it is highly important to the community to devise means to prevent those who by original infirmity are incapable of meeting them from swelling the ranks of pauperism, crime and insanity. Defining amentia, or mental deficiency, as the manifestation of an imperfect or arrested development of certain cells of the brain, in the great majority of cases due to a defect inherent in the germinal plasm, Dr. Tredgold deduces from the teachings of experience, as well as of etiology, that cure is out of the question; yet training can do much, at any rate for the milder grades of defect, though effective training involves a large expenditure of time and money. Such an expenditure, however, he argues, is not wasted if thereby such unfortunates may be prevented from drifting into pauper vagrancy, into crime, and into insanity, a course which entails upon the community a charge far in excess of that of even specialized education. $\mathrm{He}$ does not agree with the views held by some that "all patients suffering from whatever degree of mental defect should be subject to permanent detention", and contends that "so long as the feeble-minded, or any other section of society, are capable of earning an honest living, it appears unjustifiable to interfere with their liberty". At the same time, he recognizes the necessity of judicious after-care even for them, and alludes to the scope there is for philanthropic persons to form associations for this purpose, and perhaps also to provide 
industrial colonies or boarding-houses of a voluntary character. But training alone does not solve the whole problem, "since it fails in one-third, and is only partially successful in another third of the cases", and so, in addition to (1) adequate training and (2) after-care associations, Dr. Tredgold advocates (3) the establishment of industrial colonies for the permanent detention of those who are only partially self-supporting, and (4) cheaper institutions for the permanent detention of the failures. The last-mentioned class, he thinks, might fittingly be dealt with under the provisions of the "Idiots Act" so far as detention is concerned: but the difficulty everywhere, except, perhaps, in the metropolitan area, is the lack of sufficient accommodation for unimprovable imbeciles, which Dr. Tredgold thinks the county councils, either singly or in combination, should be required to provide.

\section{REFERENCE}

British Medical Journal, 14 January 1905, 88-89.

Researched by Henry Rollin, Emeritus Consultant Psychiatrist, Horton Hospital, Epsom, Surrey 